\title{
ОТНОШЕНИЕ К НЕОПРЕДЕЛЕННОСТИ И СОГЛАСИЕ СО ВЗГЛЯДАМИ РОДИТЕЛЕЙ КАК ПРЕДИКТОРЫ ИЗМЕНЕНИЯ ОТНОШЕНИЯ К РЕЛИГИИ
}

\author{
Е.В. УЛЫБИНА
}

${ }^{a}$ Российская академия народного хозяйства и государственной службы при Президенте Российской Федерачии, 119571, Россия, Москва, просп. Вернадского, д. 82-84

${ }^{b}$ Российский государственный гуманитарный университет, 125993, Россия, Москва, Миусская площадь, д. 6

\begin{abstract}
Резюме
Предмет исследования - соотношение личностных особенностей людей, изменивших и не изменивших отношение к религии после 16 лет. Определялись: уровень интолерантности и толерантности к неопределенности, уровень ориентации на социальную желательность и уровень согласия со взглядами родителей. Общая гипотеза состояла в том, что отношение к неопределенности оказывает большее, чем другие факторы, влияние на то, будет или не будет подросток верующим во взрослом возрасте. Исследование было направлено на проверку этой гипотезы. Выборку составили 333 человека от 16 до 69 лет, заполнивших анкету через интернет-формы. Анализ данных показал, что у верующих значимо выше уровень интолерантности к неопределенности, уровень ориентации на социальную желательность и согласия со взглядами родителей на религию и значимо ниже уровень интолерантности к неопределенности. Бинарная логистическая регрессия с последовательным включением подтвердила выдвинутую гипотезу, показав, что по выборке в целом отношение к религии на первом шаге предсказывается уровнем интолерантности к неопределенности, на втором - согласием с позицией родителей, а на третьем - уровнем толерантности к неопределенности. Учет направления изменения отношения к религии показал, что при переходе от неверия к вере на первом шаге вклад вносит уровень толерантности к неопределенности, на втором шаге - уровень интолерантности к неопределенности, вклад согласия со взглядами родителей не значим, а переход от веры к неверию на первом шаге предсказывается согласием со взглядами родителей на религию, на втором - уровнем интолерантности к неопределенности и на третьем - уровнем ориентации на социальную желательность. Люди становятся верующими, скорее стремясь избежать неопределенности ситуации, а остаются верующими в большей степени в согласии с позицией родителей.
\end{abstract}

Ключевые слова: толерантность к неопределенности, интолерантность к неопределенности, религиозность, изменение отношения к религии. 


\section{Введение}

Данные о связи воспитания с уровнем религиозности (D'Onofrio et al., 1999; и др.) дают возможность говорить о культурной детерминации веры, а когнитивные исследования (Atran, Norenzayan, 2004; Barrett, 2007; Gervais, Henrich, 2010; Purzycki et al., 2012) позволяют объяснять прочность религий общими для всех людей предрасположенностями в обработке информации, показывая, что религиозная вера - это альтернативный способ объяснения реальности. Для того чтобы перестать верить, необходимо некоторое усилие, преодолевающее интуитивный, принятый без дополнительных размышлений образ мира. Особое место в ряду исследований психологических оснований религий занимает изучение факторов, влияющих на изменение отношения человека к вере. В детстве отношение к религии в большинстве случаев определяется воспитанием, а в дальнейшем взгляды могут сохраниться или измениться, если они вступают в противоречие с индивидуальными особенностями переработки информации. Так, например, интуитивный когнитивный стиль предсказывает веру в Бога у взрослых в большей степени, чем религиозное воспитание и другие факторы, включая доход, уровень образования и пр. (Shenhav et al., 2012; Pennycook et al., 2012; Gervais, Norenzayan, 2012).

Представляется, что когнитивный стиль - не единственный фактор, определяющий предрасположенность к вере. Религиозные убеждения действуют в качестве буфера против тревоги и сводят к минимуму опыт ошибок (Inzlicht et al., 2009). Люди стремятся жить в понятном мире, а религиозные системы обладают высокой объяснительной силой, в определенной степени заменяя собственный анализ ситуации (Preston, Epley, 2005), что для людей с низкой переносимостью неопределенности имеет особую ценность.

Результаты исследований, подтверждающие связь веры в Бога с низкой толерантностью к неопределенности (см., например: Budner, 1962), данные о повышении религиозности при утрате чувства определенности (Laurin et al., 2008; McGregor et al., 2008; Wichman, 2010; и др.) позволили выдвинуть общую гипотезу о том, что показатели отношения к неопределенности будут предсказывать изменение отношения к религии во взрослом возрасте сильнее, чем возраст, образование, уровень согласия со взглядами родителей на религию и ориентация на социальную желательность.

Однако переход от веры к неверию требует бо́льших усилий, чем переход от неверия к вере, что позволило сформулировать частную гипотезу о том, что отказ от веры в большей степени предсказывается близостью со взглядами родителей, а отказ от неверия - отношением к неопределенности.

Целью исследования было выявление значимости вкладов отношения к неопределенности, согласия со взглядами родителей на религию, социальной желательности, возраста, пола и образования в изменении отношения к вере.

Современная ситуация в Росси представляет особый интерес для изучения факторов изменения отношения к религии, так как часть людей, преимущественно старшего возраста, получили атеистическое воспитание, а другие выросли в ситуации возвращения религии в общественное пространство и 
могли знакомиться с религиозными идеями с детства. Сегодня сохраняется ситуация, при которой принадлежность к одной из традиционных религий рассматривается как социально одобряемая позиция, но и отсутствие веры не является социально порицаемым и не создает субъекту неудобств. В этой ситуации вклад личностных особенностей в отношение к религии особенно выражен.

\section{Методы}

Для измерения отношения к неопределенности использовалась методика C. Баднера (Badner, 1962), адаптированная и стандартизированная для отечественной выборки Т.В. Корниловой и М.А. Чумаковой (2014), включающая 13 пунктов с оценкой согласия с каждым по 7-балльной шкале Лайкерта, позволяющая измерять уровень интолерантности к неопределенности (ИТН) и толерантности к неопределенности (ТН). При обработке результатов учитывались сырые баллы, так как приведенные авторами Т-баллы рассчитывались для респондентов до 30 лет.

Шкала Социальной желательности Марлоу-Крауна в адаптации Ю.Л. Ханина (Ханин, 1976), включающая 20 пунктов с вариантами ответов Да - Нет, в дальнейшем - СЖ, рассматривалась как показатель значимости социального одобрения для личности.

Для измерения близости взглядов респондентов со взглядами родителей использовался уровень согласия с утверждением «Мои родители разделяют мои взгляды на религию», в дальнейшем - CР, по 7-балльной шкале Лайкерта.

Для измерения религиозности 1) использовался уровень согласия с утверждением «Религия занимает важнейшее место в моей жизни/определяет мою жизнь», в дальнейшем - религиозность, по 7-балльной шкале Лайкерта и 2) участники должны были выбрать один из вариантов, описывающих их отношение к религии - атеист, агностик, верующий, но не принадлежу ни к какой конфессии, православный, католик, протестант, мусульманин, иудей, буддист, другое. В данной работе рассматривались ответы только православных, атеистов и агностиков.

Для контроля уровня образования участники выбирали один из вариантов ответа: среднее, незаконченное высшее, высшее, научная степень.

В качестве зависимой переменной выступал ответ на вопрос об изменении отношения к религии после 16 лет. В комментариях по поводу изменения отношения к религии респонденты отмечали и возраст 5 лет, и 15, и 35 лет и пр. Возраст 16 лет был взят как условная граница взрослости (получение паспорта), предполагающая, что человек уже способен к определенной самостоятельности суждений.

\section{Выборка и процедура}

Сбор данных проходил с февраля по апрель 2016 г., испытуемые заполняли онлайн-формы, размещенные на специализированном православном форуме в сети Вконтакте, на страницах в Фейсбуке. В исследовании учитывались 
ответы только тех респондентов, которые отнесли себя к православным (205 человек, 117 женщин, средний возраст - 33.15, и 88 мужчин, средний возраст - 34.56), атеистам или агностикам (128, из них 75 женщин, средний возраст - 33.8 года и 53 мужчины, средний возраст - 37.6).

\section{Результаты}

В таблице 1 представлено распределение мужчин и женщин в зависимости от изменения отношения к религии.

Мужчины и женщины имеют значимые различия только по уровню СЖ $(d f=331 ; t=2.994, p<0.01)$. У людей, изменивших отношение к религии, уровень СЖ значимо ниже, чем у не изменивших $(d f=165 ; t=3.052, p<0.01)$, а СР значимо выше $(t=2.977, p<0.01)$.

В таблице 2 приведены средние значения по показателям у верующих и неверующих. Религиозность не имеет значимых связей с возрастом, но прямо коррелирует с ИТН $(r=0.357, p<0.001)$, с СР $(r=0.322, p<0.001)$, с СЖ $(r=$ $0.139, p<0.05)$ и обратно - с ТН $(r=-0.220, p<0.001)$. Связь СР, ИТН, ТН, СЖ с возрастом не значима. СЖ прямо связана с СР $(r=0.182, p<0.01)$, связь с ИТН и ТН не значима. Дисперсионный анализ показал отсутствие значимых различий в уровне религиозности у людей с разным уровнем образования.

Результаты регрессионного анализа показали, что в уровень религиозности вносят вклад уровень ИТН $(\beta=0.299, p<0.001)$, СР $(\beta=0.244, p<0.001)$, ТН $(\beta=-0.164, \mathrm{p}<0.001)$ и СЖ $(\beta=0.142, p<0.001), R^{2}=0.261$.

Таблица 1

Описательная статистика распределения мужчин и женщин в зависимости от изменения отношения к религии

\begin{tabular}{|l|c|c|c|}
\hline \multicolumn{1}{|c|}{ Испытуемые } & $\begin{array}{c}\text { Средний } \\
\text { возраст }\end{array}$ & $\begin{array}{c}\text { Количество } \\
\text { участников }\end{array}$ & $\begin{array}{c}\text { Стандартное } \\
\text { отклонение }\end{array}$ \\
\hline Женщины всего & 34.00 & 192 & 11.55 \\
\hline $\begin{array}{l}\text { Женщины, которые изменили отношение } \\
\text { к религии }\end{array}$ & 34.90 & 93 & 11.44 \\
\hline $\begin{array}{l}\text { Женщины, которые не изменили } \\
\text { отношения к религии }\end{array}$ & 33.15 & 99 & 11.66 \\
\hline Всего & 35.61 & 141 & 10.81 \\
\hline $\begin{array}{l}\text { Мужчины, которые изменили отношение } \\
\text { к религии }\end{array}$ & 36.95 & 74 & 9.81 \\
\hline $\begin{array}{l}\text { Мужчины, которые не изменили } \\
\text { отношение к религии }\end{array}$ & 34.13 & 67 & 11.72 \\
\hline Всего & 34.68 & 333 & 11.26 \\
\hline
\end{tabular}


Таблииа 2

Результаты сравнения неверующих и верующих

\begin{tabular}{|l|c|c|c|c|c|}
\hline & \multicolumn{2}{|c|}{ Неверующие } & \multicolumn{2}{c|}{ Верующие } & \multirow{2}{*}{ t-критерий } \\
Стьюдента \\
\cline { 1 - 4 } & $\mathrm{M}$ & $\mathrm{SD}$ & $\mathrm{M}$ & $\mathrm{SD}$ & \multirow{2}{*}{ Возраст } \\
\cline { 1 - 4 } & 36.023 & 10.737 & 33.761 & 11.315 & 1.810 \\
\hline СР & 3.523 & 1.972 & 4.820 & 1.785 & $-6.188^{* * *}$ \\
\hline ИТН & 24.117 & 7.203 & 29.834 & 7.361 & $-6.951^{* * *}$ \\
\hline ТН & 30.367 & 5.700 & 27.976 & 4.827 & $4.099^{* * *}$ \\
\hline СЖ & 5.750 & 3.155 & 6.780 & 3.815 & $-2.558^{*}$ \\
\hline
\end{tabular}

${ }^{*} p<0.05,{ }^{* * *} p<0.001$.

Таблица 3

Результаты сравнения постоянно верующих и бывших верующих

\begin{tabular}{|l|c|c|c|c|c|}
\hline & \multicolumn{2}{|c|}{ Постоянно верующие } & \multicolumn{2}{c|}{ Бывшие верующие } & \multirow{2}{*}{$\begin{array}{c}\text { t-критерий } \\
\text { Стьюдента }\end{array}$} \\
\cline { 1 - 5 } & $\mathrm{M}$ & $\mathrm{SD}$ & $\mathrm{M}$ & $\mathrm{SD}$ & -1.840 \\
\hline Возраст & 30.955 & 11.032 & 34.233 & 10.041 & $7.937^{* * *}$ \\
\hline СР & 5.136 & 1.620 & 2.950 & 1.682 & $6.554^{* * *}$ \\
\hline ИТН & 30.080 & 7.728 & 22.283 & 6.070 & $-2.010^{*}$ \\
\hline ТН & 28.205 & 4.885 & 30.067 & 6.370 & $3.733^{* * *}$ \\
\hline СЖ & 7.455 & 4.017 & 5.217 & 2.817 & \\
\hline
\end{tabular}

${ }^{*} p<0.05,{ }^{* * *} p<0.001$.

В целом по выборке то, будет ли человек верующим или неверующим, бинарная логистическая регрессия с последовательным включением (далее в тексте - бинарная логистическая регрессия), в которую в качестве предикторов вошли: возраст, пол, образование, СР, СЖ, ИТН и ТН, позволяет дать предсказание на уровне 74.8\%. На первом шаге в нее включается уровень ИТН $(\beta=0.104, \mathrm{p}<0.001)$, на втором - уровень СР $(\beta=0.337, p<0.001)$, далее - уровень ТН $(\beta=-0.101, p<0.001)$.

Для анализа относительной роли факторов, вносящих вклад в отказ от веры и отказ от неверия, выборка была разбита на две части: постоянно верующих и бывших верующих (таблица 3) и постоянно неверующих и бывших неверующих (таблица 4).

Бинарная логистическая регрессия в первом случае дает 79.7\% верных прогнозов. На первом шаге в нее был включен уровень СР $(\beta=0.632, p<0.001)$, на втором - ИТН $(\beta=0.143, p<0.001)$, на третьем - СЖ $(\beta=0.138, p<0.05)$.

Во втором случае в бинарную логистическую регрессию на первом шаге был включен уровень ТН $(\beta=0.123, p<0.001)$, на втором - ИТН $(\beta=-0.077$, $p<0.001)$. Процентный показатель верных прогнозов равен 67.6. 
Таблица 4

Результаты сравнения бывших неверующих и постоянно неверующих

\begin{tabular}{|c|c|c|c|c|c|}
\hline & \multicolumn{2}{|c|}{ Бывшие неверующие } & \multicolumn{2}{|c|}{ Постоянно неверующие } & \multirow{2}{*}{$\begin{array}{l}\text { t-критерий } \\
\text { Стьюдента }\end{array}$} \\
\hline & $\mathrm{M}$ & $\mathrm{SD}$ & $\mathrm{M}$ & $\mathrm{SD}$ & \\
\hline Возраст & 35.872 & 11.110 & 37.868 & 11.686 & -1.156 \\
\hline $\mathrm{CP}$ & 4.581 & 1.872 & 4.029 & 2.080 & 1.855 \\
\hline ИТН & 29.650 & 7.099 & 25.735 & 7.761 & $3.493^{* *}$ \\
\hline TH & 27.803 & 4.796 & 30.632 & 5.069 & $-3.788^{* * *}$ \\
\hline СЖ & 6.274 & 3.590 & 6.221 & 3.376 & 0.099 \\
\hline
\end{tabular}

** $p<0.01,{ }^{* * *} p<0.001$.

\section{Обсуждение результатов}

Больший вклад в вероятность того, будет ли взрослый человек верующим, вносит ИТН, что подтверждает общую гипотезу в целом. Вместе с тем показатель СР значимо связан с уровнем религиозности и вошел в число предикторов на втором шаге, что позволяет говорить о значимости влияния семьи на отношение к религии детей. Отсутствие возраста в числе значимых предикторов приводит к выводу о том, что различия в опыте людей старшего и младшего поколения, выросших в разных условиях, не оказывают заметного влияния на отношение к религии. При изменении культурной ситуации те, кто имел к этому предрасположенность, стали верующими, а остальные остаются неверующими и сегодня.

Переход от неверия к вере обусловлен индивидуальными особенностями отношения к неопределенности, уровнем ТН, а сохранение веры - в большей степени уровнем СР, что подтверждает и частную гипотезу. В целом по выборке уровень СЖ и СР у верующих выше, чем у неверующих, вера оценивается как социально желательная позиция, а родители и верующих, и неверующих респондентов в большинстве случаев верят в Бога. Это создает асимметричную ситуацию, при которой переход от веры к неверию происходит скорее вопреки мировоззрению родителей, а переход от неверия к вере - в согласии с мировоззрением родителей.

В результате неверующие, изменяющие мировоззрение, действуют в согласии со средой, а для людей с низкой ТН вера предлагает более комфортную модель мира и определяющим показателем становится отношение к неопределенности. Это показывает, что переход к вере происходит не под давлением среды, а на основе личной предрасположенности, которой среда может благоприятствовать.

Выбор неверия для верующих требует больших усилий, включающих в себя преодоление интуитивных предрасположенностей и возможного влияния родителей, так как у тех, кто стал неверующим после 16 лет, можно предположить 
религиозное воспитание в детстве и наличие верующих родителей. Верующими остаются люди, чьи взгляды находятся в согласии со взглядами родителей, избегающие неопределенности и ориентированные на социальную желательность.

Верующие люди с высокой ТН и низким уровнем ИТН при прочих равных имеют меньше стимулов менять мировоззрение, находя возможности избегать однозначности внутри веры, тогда как низкая ТН и высокая ИТН у неверующих стимулируют обращение к религии, функционирующей, по словам M. Хогга с соавт. (Hogg et al., 2010), как мощная, всеобъемлющая идеологическая система, дающая смысл и цель существованию, определяющая нормативные практики поведения в повседневной жизни и ориентиры морального выбора.

Полученные результаты носят предварительный характер и нуждаются в проверке на большей выборке.

\section{Литература}

Корнилова, Т. В., Чумакова, М. А. (2014). Шкалы толерантности и интолерантности к неопределенности в модификации опросника С. Баднера. Экспериментальная психология, 7(1), 92-110. Ханин, Ю. Л. (1976). Шкала Марлоу-Кроуна для исследования мотивации одобрения. Л.: НИИ ФК.

Ссылки на зарубежные источники см. в разделе References после англоязычного блока.

Улыбина Елена Викторовна - профессор, кафедра общей психологии, Институт общественных наук, Российская академия народного хозяйства и государственной службы при Президенте Российской Федерации, доктор психологических наук, профессор.

Сфера научных интересов: психология религии, толерантность к неопределенности, психология идентичности, гендерная психология, психология личности, общая психология. Контакты: evulbn@gmail.com

Бакланова Надежда Вячеславовна - выпускница, Институт психологии им. Л.С. Выготского, Российский государственный гуманитарный университет.

Сфера научных интересов: психология религии, феномен религиозности, феномен толерантности к неопределенности.

Контакты: nadezhdanezabludka@gmail.com 


\title{
Attitude to Ambiguity and Agreement with Parents' Beliefs as Predictors of Attitude Shift to Religion
}

\author{
E.V. Ulybina ${ }^{a}$, N.V. Baklanova ${ }^{b}$
}

\begin{abstract}
${ }^{a}$ Russian Presidential Academy of National Economy and Public Administration (The Presidential Academy, RANEPA), 82-84, Prospect Vernadskogo, Moscow, 119571, Russian Federation

${ }^{b}$ L.S.Vygotsky Institute for Psychology of the Russian State University for the Humanities, 6 Miusskaya sq., Moscow, 125993, Russian Federation
\end{abstract}

\begin{abstract}
The subject of this research is the correlation of personality traits of people who have changed their attitude to religion after the age of 16: the level of intolerance/tolerance for ambiguity, the level of orientation to social desirability and the level of agreement with parents' beliefs depending on course of changes. The research sample consisted of 492 people from 16 to 69, 102 of which answered questions in person, whereas others - via Internet forms. The results showed that religious people have significantly higher level of intolerance for ambiguity, orientation to social desirability and agreement with parents' beliefs on religion and significantly lower level of tolerance for ambiguity. Stepwise binary logistic regression showed the following results in the sample on the whole: whether a person will become religious or not as an adult can be predicted in the first step by agreement with parents' beliefs on religion, in the second step - by the level of intolerance for ambiguity and in the third step - by the level of orientation to social desirability. However, the record of course of attitude changes to religion showed that when switching from disbelief to belief, more contribution is made by attitude to ambiguity: by the level of intolerance for ambiguity for men, the level of tolerance for ambiguity for women, and in terms of faith preservation - by agreement with parents` beliefs on religion. People become religious rather attempting to avoid ambiguity of situation, and remain religious mostly in agreement with parent' position.
\end{abstract}

Keywords: intolerance for ambiguity, tolerance for ambiguity, psychology of religion, a change of attitude towards religion.

\section{References}

Atran, S., \& Norenzayan, A. (2004). Religion's evolutionary landscape: Counterintuition, commitment, compassion, communion. Behavioral and Brain Sciences, 27(6), 713-730. doi:10.1017/S0140525X04000172

Barrett, J. L. (2007). Cognitive science of religion: What is it and why is it? Religion Compass, 1(6), 768-786. doi:10.1111/j.1749-8171.2007.00042.x

Budner, S. (1962). Intolerance of ambiguity as a personality variable. Journal of Personality, 30(1), 29 50. doi:10.1111/j.1467-6494.1962.tb02303.x

D’Onofrio, B. M., Eaves, L. J., Murrelle, L., Maes, H. H., \& Spilka, B. (1999). Understanding biological and social influences on religious affiliation, attitudes, and behaviors: A behavior genetic perspective. Journal of Personality, 67(6), 953-984. doi:10.1111/1467-6494.00079 
Gervais, W. M., \& Henrich, J. (2010). The Zeus problem: Why representational content biases cannot explain faith in gods. Journal of Cognition and Culture, 10(3), 383-389. doi:10.1163/156853710X531249

Gervais, W. M., \& Norenzayan, A. (2012). Analytic thinking promotes religious disbelief. Science, 336(6080), 493-496. doi:10.1126/science.1215647

Hogg, M. A., Adelman, J. R., \& Blagg, R. D. (2010). Religion in the face of uncertainty: An uncertainty-identity theory account of religiousness. Personality and Social Psychology Review, 14(1), 72-83. doi:10.1177/1088868309349692

Inzlicht, M., McGregor, I., Hirsh, J. B., \& Nash, K. (2009). Neural markers of religious conviction. Psychological Science, 20(3), 385-392.

Khanin, Yu. L. (1976). Shkala Marlou-Krouna dlya issledovaniya motivatsii odobreniya [MarloweCrowne scale to study motivation of approval]. Leningrad: NII FK. (in Russian)

Kornilova, T. V., \& Chumakova, M. A. (2014). Tolerance and intolerance of ambiguity in the modification of Budner's questionnaire. Eksperimental'naya Psihologiya [Experimental Psychology (Russia)], 7(1), 92-110. (in Russian)

Laurin, K., Kay, A. C., \& Moscovitch, D. A. (2008). On the belief in God: Towards an understanding of the emotional substrates of compensatory control. Journal of Experimental Social Psychology, 44(6), 1559-1562. doi:10.1016/j.jesp.2008.07.007

McGregor, I., Haji, R., Nash, K. A., \& Teper, R. (2008). Religious zeal and the uncertain self. Basic and Applied Social Psychology, 30(2), 183-188. doi:10.1080/01973530802209251

Pennycook, G., Cheyne, J. A., Seli, P., Koehler, D. J., \& Fugelsang, J. A. (2012). Analytic cognitive style predicts religious and paranormal belief. Cognition, 123(3), 335-346.

Preston, J., \& Epley, N. (2005). Explanations versus applications: The explanatory power of valuable beliefs. Psychological Science, 16(10), 826-832. doi:10.1111/j.1467-9280.2005.01621.x

Purzycki, B. G., Finkel, D. N., Shaver, J., Wales, N., Cohen, A. B., \& Sosis, R. (2012). What does God know? Supernatural agents' access to socially strategic and non strategic information. Cognitive Science, 36(5), 846-869. doi:10.1111/j.1551-6709.2012.01242.x

Shenhav, A., Rand, D. G., \& Greene, J. D. (2012). Divine intuition: cognitive style influences belief in God. Journal of Experimental Psychology: General, 141(3), 423-428. doi:10.1037/a0025391

Wichman, A. L. (2010). Uncertainty and religious reactivity: Uncertainty compensation, repair, and inoculation. European Journal of Social Psychology, 40(1), 35-42. doi:10.1002/ejsp.712

Elena V. Ulybina - professor, Department of General Psychology, Institute of Social Sciences, Russian Academy of National Economy and Public Administration, D.Sc.

Research area: psychology of religion, tolerance to uncertainty, identity psychology, gender psychology, personality psychology, general psychology.

E-mail: evulbn@gmail.com

Nadezhda V. Baklanova - graduate student, L.S. Vygotsky Institute for Psychology, Russian State University for the Humanities.

Research area: psychology of religion, phenomenon of religiosity, phenomenon of tolerance to uncertainty.

E-mail: nadezhdanezabludka@gmail.com 